RESEARCH REPORT

\title{
Material, psychosocial, and behavioural factors in the explanation of educational inequalities in mortality in the Netherlands
}

\author{
Floor V A van Oort, Frank J van Lenthe, Johan P Mackenbach
}

J Epidemiol Community Health 2005;59:214-220. doi: 10.1136/jech.2003.016493

See end of article for authors' affiliations ....................

Correspondence to: Ms F V A van Oort, Erasmus MC, Department of Public Health, PO Box 1738, 3000 DR Rotterdam, Netherlands: f.vanoort@erasmusmc.nl

Accepted for publication 28 May 2004

Study objectives: To assess the direct and indirect contributions of material, behavioural, and psychosocial factors to the explanation of educational inequalities in mortality simultaneously.

Design: Prospective observational study (1991-1998).

Setting: General population from south east Netherlands.

Participants: 3979 men and women aged 15-74 years without severe chronic disease at baseline (1991).

Main results: Material factors (type of health insurance, financial problems, and housing tenure), psychosocial factors (life events and external locus of control), and behavioural factors (smoking habits and physical activity) together reduced the relative risk of mortality of the lowest educated group from 2.57 $(95 \% \mathrm{Cl} 1.43$ to 4.64$)$ to $1.01(95 \% \mathrm{Cl} 0.50$ to 2.03$)$. Of these three groups of factors, material factors contributed most to the educational inequalities. Part of the contribution of material factors was via psychosocial factors and part via behavioural factors. Psychosocial factors contributed to educational inequalities, partly via behavioural factors. Behavioural and psychosocial factors contributed only marginally to the explanation independent of material factors.

Conclusion: Educational inequalities in mortality were explained by material, psychosocial, and behavioural factors. Material factors contributed most to the explanation, partly via psychosocial and behavioural factors. Improving the material situation of lower educated people may substantially reduce educational inequalities in mortality, partly via the psychosocial and behavioural consequences of improved material circumstances.

$\mathrm{L}$ ow socioeconomic position has consistently been associated with an increased risk of mortality. ${ }^{12}$ However, the - mechanisms underlying this association are not completely understood. Suggested explanations include unequal distribution of health risk behaviours (for example, smoking), material factors (for example, financial difficulties), and psychosocial resources and stress related factors (for example, life events, lack of social support). ${ }^{34}$ Probably these factors together can explain a large part of the inequalities in mortality. However, less is known about which of the explanations is most important. The relative importance of different (groups of) explanatory factors is still under debate. Especially the relative importance of material and psychosocial factors for the explanation of socioeconomic inequalities in mortality is not yet clear. ${ }^{5}$ Some argue for a primarily material explanation, in which inequalities in health are the result of differential exposure to material disadvantage, ${ }^{6}$ whereas others argue that absolute material standards cannot explain inequalities in health and that inequalities can probably be largely explained by psychosocial factors underlying the perception of relative position in the social hierarchy. ${ }^{78}$ Studies that focused on only one mechanism indicate that multiple pathways almost certainly underlie the inequalities. ${ }^{9-11}$ Furthermore, the mechanisms probably are interrelated, indicating that some mechanisms work through others rather than work independently from each other. ${ }^{10-13}$ It is important to acknowledge these indirect pathways in the assessment of the relative importance of different explanatory mechanisms. To our knowledge no study has combined these three groups of explanatory factors (material, behavioural, psychosocial) in an attempt to explain educational inequalities in mortality.
A simplified causal model (fig 1$)^{3}{ }^{14}$ suggests three pathways from level of education to mortality: through (1) material factors, ${ }^{10}(2)$ psychosocial and stress related factors, ${ }^{15}$ and (3) behavioural factors. ${ }^{13}$ Material factors may affect mortality either directly or indirectly, via behavioural and via psychosocial factors. ${ }^{8} 1013$ Psychosocial factors may also exert a direct and an indirect effect, through behavioural factors. ${ }^{8} 12$

Educational inequalities in mortality can only be reduced when the causal mechanisms are understood and when important intermediate factors are identified. Therefore the aim of this paper is to simultaneously assess the direct and indirect contributions of material, psychosocial, and behavioural factors to the explanation of educational inequalities in mortality. Furthermore, we aim to point out the relative importance of the three groups of explanatory factors.

\section{METHODS}

\section{Study population}

Data were collected within the framework of the prospective GLOBE study. ${ }^{3}$ The GLOBE acronym refers to Gezondheid en LevensOmstandigheden Bevolking Eindhoven en omstreken (Health and Living Conditions of the population of Eindhoven and surroundings). In 1991 a random sample of 27070 non-institutionalised Dutch persons (aged 15-74 years) drawn from 18 municipal population registers in south eastern Netherlands, was sent a postal questionnaire. The response rate was $70.1 \%(\mathrm{n}=18973)$ and response was not substantially different for age, sex, marital status, level of urbanisation, or social class. ${ }^{3}$ Two sub-samples of the respondents were approached for a structured interview at the respondents' home. One sub-sample overrepresented 


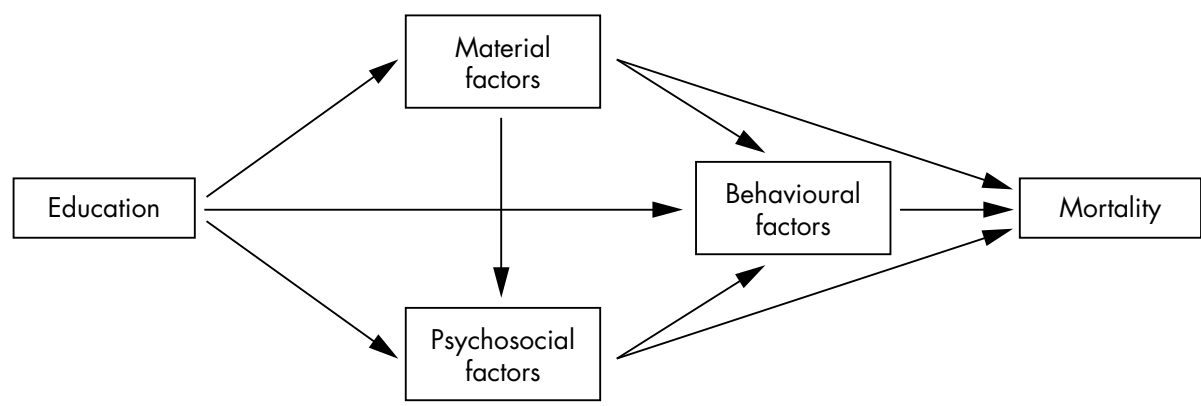

Figure 1 Simplified conceptual model with independent and indirect contributions of material factors, behavioural factors, and psychosocial factors.

people with chronic lung disease, severe heart disease, diabetes, and persistent back trouble (response $72.3 \%$, $\mathrm{n}=2865) .{ }^{16}$ The other sub-sample was a random sample of respondents to the postal questionnaire (response $79.4 \%$, $\mathrm{n}=2802$ ). Differential non-response only occurred in the sub-sample that overrepresented chronically ill persons, where younger and single people less often agreed to participate. ${ }^{16}$ Altogether 1463 (26\%) people with severe chronic disease in 1991 (chronic obstructive pulmonary disease, heart disease, stroke, renal disease, diabetes, cancer) were excluded as well as people with missing values on either level of education or on self reported severe chronic disease in 1991 (total excluded $\mathrm{n}=1580,28 \%$ ); 4087 respondents were eligible for the analyses.

\section{Level of education and mortality}

Four levels of education were distinguished: primary education only (lowest), lower vocational school and lower secondary school (low), intermediate vocational school and intermediate or higher secondary school (higher), and higher vocational school and university (highest). Students were classified by their current training.

The follow up of all subjects started on 1 April 1991. We used data from the follow up until 1998. Information about all cause mortality was collected annually via municipal population registers. These registers cover the population completely and are maintained continuously with respect to deaths and changes of address.

\section{Material, behavioural, and psychosocial factors}

Categories are indicated in parentheses. Material and behavioural factors were derived from the postal questionnaire. A question on the difficulty a person had in paying bills, food, rent, electricity, and so forth during the previous year measured the extent of financial difficulties (no difficulties, small difficulties, and big difficulties). Other material factors were type of health insurance (public, private), car owning (yes, no), and housing tenure (owning, renting). Most people in the Netherlands with an income above a certain level are privately insured, while lower income groups receive public insurance, therefore type of insurance is a crude proxy for level of income
Health behaviour factors were smoking (current smokers, former smokers, non-smokers), alcohol use (excessive, moderate, abstaining), and physical inactivity (inactive, moderately active, active). Excessive alcohol consumption was defined as drinking at least six alcoholic beverages per day on more than two days per week, or four to five alcoholic beverages per day on more than four days per week. ${ }^{17}$ Physical activity in leisure time was scored with number of hours per week spent on "sport activity" given twice as much weight as "gardening, cycling, and walking". Cut off points were two and five hours per week.

The postal questionnaire provided information on life events, and the interview information on other psychosocial factors. Nine negative life events, among others negative change in financial position, severe disease of partner, and divorce, in the preceding year were asked for (no event, 1, 2, 3 or more events).${ }^{18}$ Other psychosocial factors were long lasting difficulties (no problems, 1, 2, 3 or more problems), emotional social support (thirds), active and avoiding coping styles (thirds), and locus of control (quintiles). ${ }^{19}{ }^{20}$ Long lasting difficulties were measured with an 18 item checklist covering financial problems, social deprivation, neighbourhood problems, health problems of others, and problems in relationships. ${ }^{21}$ Emotional social support was measured with a six item Dutch questionnaire asking for the emotional support provided by the respondent's three most significant people (Cronbach's $\alpha 0.60) .{ }^{22}$ Active and avoiding coping style were measured by the Utrechtse coping list (active coping style eight items, Cronbach's $\alpha 0.80$; avoiding coping style seven items, Cronbach's $\alpha$ 0.68). ${ }^{23}$ An active coping style implies that a subject generally takes action in case of problems, an avoiding coping style implies that a subject tries to stay away from any trouble and is passive in case of problems.

\section{Statistical analyses}

All analyses were weighted to make the sample representative for the original Globe respondents. Those risk factors with a significant risk for mortality $(p \leqslant 0.05)$, and a negative association with level of education were selected for explanatory analyses. We calculated the hazard ratios ${ }^{24}$ for levels of education adjusted for age and gender (reference model) and further adjusted for material factors, behavioural factors, and for psychosocial factors separately, adjusted for

Table 1 General characteristics of the study population by level of education

\begin{tabular}{lllll}
\hline & \multicolumn{2}{l}{ Level of education } & & \\
\cline { 2 - 5 } & lowest & low & higher & highest \\
\hline Number (\%) & $760(19)$ & $1554(38)$ & $945(23)$ & $828(20)$ \\
Age (y) (SD) & $57(12)$ & $48(14)$ & $40(17)$ & $43(15)$ \\
$\%$ Male* & 39 & 39 & 52 & 69 \\
$\%$ Deceased ${ }^{*} \dagger$ & 6 & 3 & 4 & 2 \\
\hline${ }^{*}$ Column percentage; tdirectly standardised for age and gender. \\
\hline
\end{tabular}


Table 2 Hazard ratios for mortality and age and gender standardised prevalence rates by level of education of material, behavioural, and psychosocial explanatory factors

\begin{tabular}{|c|c|c|c|c|c|c|c|}
\hline & \multirow[b]{2}{*}{ HR } & \multirow[b]{2}{*}{$95 \% \mathrm{Cl}$} & \multicolumn{4}{|c|}{ Level of education } & \multirow[b]{2}{*}{$\mathrm{p}$ Value } \\
\hline & & & lowest & low & higher & highest & \\
\hline \multicolumn{8}{|l|}{ Material factors } \\
\hline \multicolumn{8}{|l|}{ Health insurance $(n=4069)$} \\
\hline Public & 2.12 & 1.40 to 3.21 & 87 & 67 & 47 & 25 & $<0.0001$ \\
\hline Private & 1.00 & & 13 & 33 & 53 & 75 & $<0.0001$ \\
\hline \multicolumn{8}{|l|}{ Financial difficulties ( $n=4007)$} \\
\hline Big difficulties & 3.02 & 1.57 to 5.81 & 7 & 3 & 3 & 2 & $<0.0001$ \\
\hline Small difficulties & 1.28 & 0.83 to 1.97 & 25 & 16 & 12 & 9 & $<0.0001$ \\
\hline No difficulties & 1.00 & & 69 & 81 & 85 & 90 & $<0.0001$ \\
\hline \multicolumn{8}{|l|}{ Housing tenure $(n=4065)$} \\
\hline Rented house & 1.47 & 1.03 to 2.10 & 67 & 46 & 31 & 31 & $<0.0001$ \\
\hline Owned house & 1.00 & & 33 & 54 & 69 & 69 & $<0.0001$ \\
\hline \multirow{2}{*}{\multicolumn{8}{|c|}{$\begin{array}{l}\text { Behavioural factors } \\
\text { Smoking ( } \mathrm{n}=4056 \text { ) }\end{array}$}} \\
\hline & 2.32 & 1.44 to 3.73 & 44 & & 32 & 27 & $<0.0001$ \\
\hline Former smoker & $\begin{array}{l}2.22 \\
1.19\end{array}$ & 0.71 to 2.00 & $\begin{array}{l}44 \\
22\end{array}$ & 30 & 35 & 32 & $<0.0001$ \\
\hline Never smoker & 1.00 & & 34 & 31 & 33 & 42 & 0.0006 \\
\hline \multicolumn{8}{|l|}{ Physical activity ( $n=4007$ ) } \\
\hline Inactive & 3.14 & 1.77 to 5.60 & 16 & 14 & 13 & 9 & 0.0009 \\
\hline Moderately active & 2.14 & 1.29 to 3.53 & 60 & 51 & 45 & 48 & $<0.0001$ \\
\hline Active & 1.00 & & 24 & 34 & 42 & 42 & $<0.0001$ \\
\hline \multicolumn{8}{|l|}{ Psychosocial factors } \\
\hline \multicolumn{8}{|l|}{ Life events $(n=4046)$} \\
\hline 0 & 1.00 & & 47 & 57 & 54 & 50 & 0.60 \\
\hline 1 & 1.62 & 1.12 to 2.35 & 33 & 27 & 30 & 32 & 0.66 \\
\hline 2 & 1.67 & 1.00 to 2.79 & 14 & 12 & 12 & 14 & 0.81 \\
\hline$\geqslant 3$ & 2.66 & 1.32 to 5.35 & 6 & 4 & 4 & 3 & 0.007 \\
\hline \multicolumn{8}{|l|}{ Locus of control $(n=4016)$} \\
\hline Internal locus of control (q1) & 1.00 & & 7 & 14 & 23 & 40 & $<0.0001$ \\
\hline 2nd quintile & 1.83 & 0.83 to 4.02 & 14 & 21 & 26 & 28 & $<0.0001$ \\
\hline 3rd quintile & 1.65 & 0.73 to 3.70 & 13 & 17 & 19 & 15 & 0.25 \\
\hline 4th quintile & 1.49 & 0.68 to 3.26 & 26 & 24 & 19 & 11 & $<0.0001$ \\
\hline External locus of control (q5) & 2.19 & 1.03 to 4.70 & 39 & 25 & 13 & 5 & $<0.0001$ \\
\hline \multicolumn{8}{|c|}{$\begin{array}{l}\text { Hazard ratios (HR) were corrected for age, gender, and level of education. Hazard ratios and percentages were } \\
\text { weighted to make the sample representative for the original GLOBE respondents. The number of respondents varies } \\
\text { because the number of missing values on the individual risk factors varied. } p \text { Values are for trend test by level of } \\
\text { education. }\end{array}$} \\
\hline
\end{tabular}

combinations of two groups of factors, and finally adjusted for all explanatory factors simultaneously. For each regression model we calculated the percentage change in hazard ratios of each level of education $\left(100 \times\left[\mathrm{HR}_{\text {reference model }}-\mathrm{HR}_{+}\right.\right.$ explanatory factors $\left.] /\left[\mathrm{HR}_{\text {reference model }}-\mathrm{l}\right]\right) .{ }^{25}{ }^{26}$ One of the main advantages of this method is that it can be used to estimate direct and indirect contributions of explanatory factors. One limitation is that the percentage change can be similar for different absolute changes in hazard ratios. However, all contributions were calculated relatively to the same hazard ratios, which were also presented. Therefore, we believe that this limitation has a limited effect on our results. We set the

Table 3 Hazard ratios for mortality for levels of education, crude and adjusted for material, behavioural, and psychosocial explanatory factors $(n=3979)$

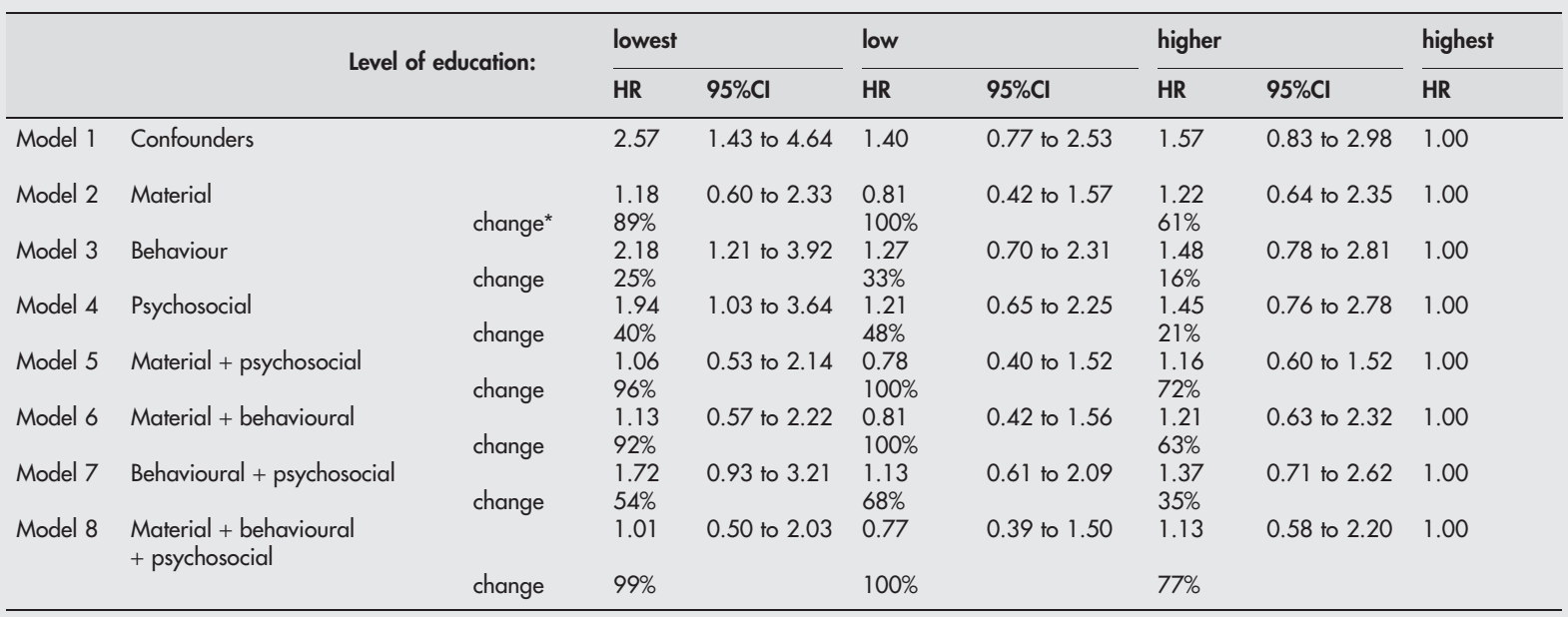

Confounders were age and gender. Hazard ratios (HR) were weighted to make the sample representative for the original GLOBE respondents. Material factors: health insurance, housing tenure, financial deprivation; behavioural factors: smoking, physical activity; psychosocial factors: life events, locus of control. *Changes in hazard ratio were calculated by: $100 \times\left[\left(\mathrm{HR}_{(+ \text {confounders })}-\mathrm{HR}_{(+ \text {explanatory factors })}\right) /\left(\mathrm{HR}_{(+ \text {confounders })}-1\right)\right]$. 
change in hazard ratio at $100 \%$ when a hazard ratio was lower than 1. We did this because the interest of this study was in changes relative to the hazard ratio of the highest educated group, which by definition is 1 . By comparing the models with two groups of explanatory factors and the corresponding two models with each one group of explanatory factors we were able to distinguish the independent and indirect (for example, contribution of material factors through behavioural factors) contributions. See appendix for more detailed information. We used SAS statistical software (SAS Institute, Cary, USA) for all analyses.

A
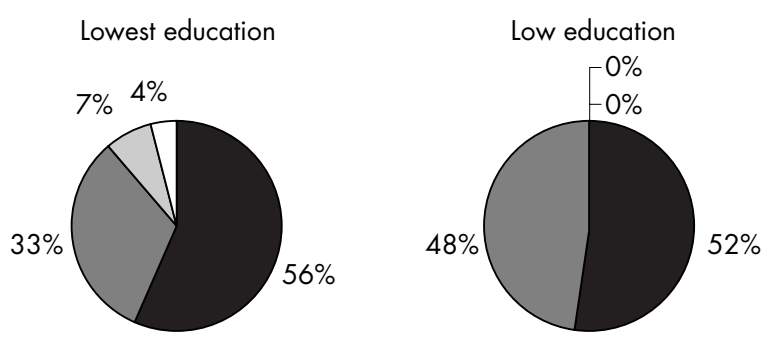

Independent effect material factors Indirect effect material factors via psychosocial factors Independent effect psychosocial factors Not explained

B
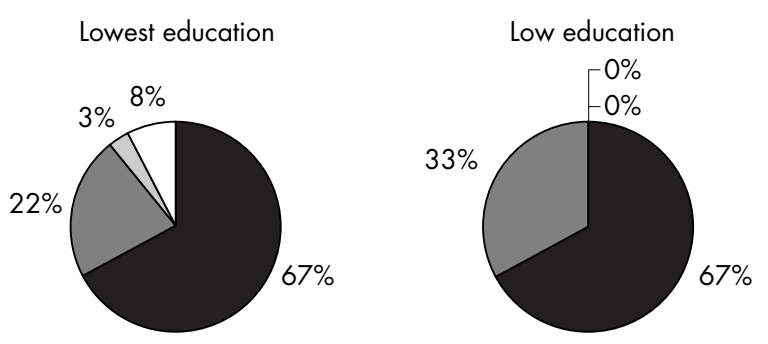

Independent effect material factors

Indirect effect material factors via behavioural factors

Independent effect behavioural factors

Not explained

C

Lowest education

Low education
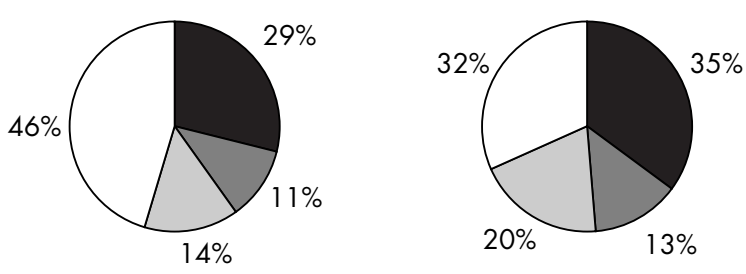

Independent effect psychosocial factors

Indirect effect psychosocial factors via behavioural factors Independent effect behavioural factors

Not explained

\section{RESULTS}

Table 1 shows general characteristics of the study population by level of education. Health insurance, financial difficulties and housing tenure (material factors), smoking and physical activity (behavioural factors) and life events, and locus of control (psychosocial factors) were associated with both mortality and level of education (table 2). These factors were included in the explanatory models. Of the nine life events death of a family member or friend, negative change in financial situation, divorce, and partner's loss of job were significantly $(p<0.10)$ associated with mortality. Hazard

Figure 2 (A) Independent and indirect contributions of material factors and psychosocial factors to the explanation of the mortality hazard ratios of levels of education. The highest educated people were reference group. (B) Independent and indirect contributions of material factors and behavioural factors to the explanation of the

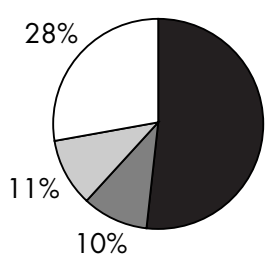
$51 \%$ mortality hazard ratios of levels of education. The highest educated people were reference group. (C) Independent and indirect contributions of psychosocial factors and behavioural factors to the explanation of the mortality hazard ratios of levels of education. The highest educated people were reference group. See appendix for the calculation of the independent and indirect contributions of and psychosocial and behavioural factors.

Higher education

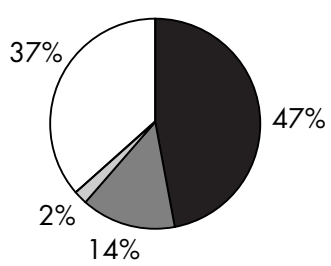

Higher education

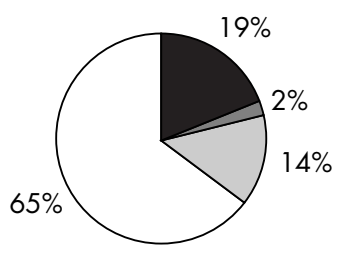


ratios and prevalence rates by level of education for other explanatory factors are available on request.

Compared with the highest educational level the risk of mortality was increased in all levels of education, although not statistically significant for all levels of education (table 3 , model 1), with the highest risk in the lowest educated group (HR 2.57; 95\% CI 1.43 to 4.64). Adjustment for material factors lowered the hazard ratios most (model 2), followed by psychosocial factors (model 4) and then behavioural factors (model 3).

Adjustment for material and psychosocial factors simultaneously (table 3, model 5) lowered the hazard ratios 7\% to $9 \%$ more than adjustment for material factors only. This indicated that part of the contribution of material factors was through psychosocial factors ( $10 \%$ to $48 \%$, fig $2 \mathrm{~A}$ ) and that the independent contribution of psychosocial factors was small but higher than the independent contribution of behavioural factors ( $0 \%$ to $11 \%$, fig $2 \mathrm{~A}$ ).

Adjustment for material and behavioural factors simultaneously (table 3, model 6) lowered the risk by an additional $2 \%$ to $3 \%$ compared with adjustment for material factors only. This indicated that part of the contribution of material factors goes through behavioural factors and that the independent contribution of behavioural factors was very small ( $0 \%$ to $3 \%$, fig $2 \mathrm{~B}$ ). Furthermore, figure $2 \mathrm{~B}$ shows that the independent contribution of material factors was higher than the indirect contribution through behavioural factors ( $47 \%$ to $67 \%$ compared with $14 \%$ to $33 \%$ ).

Adjustment for psychosocial and behavioural factors simultaneously (table 3, model 7) showed a $14 \%$ to $35 \%$ further lowering than adjustment for psychosocial factors only, indicating both independent effects of behavioural and psychosocial factors and also an indirect contribution of psychosocial factors through behavioural factors. Figure 2C shows that both independent contributions of psychosocial and behavioural factors were higher than the indirect contribution of psychosocial factors through behavioural factors.

Finally the full model (table 3, model 8) with material, behavioural, and psychosocial factors shows a complete explanation of the hazard ratios of the two lowest educated groups and a large proportion (77\%) explained of the hazard ratio of the second highest group.

\section{DISCUSSION}

Educational inequalities in mortality were explained by material, psychosocial, and behavioural factors. Material factors contributed most to the explanation, partly via psychosocial and via behavioural factors. Part of the contribution of psychosocial factors was via behavioural factors. Behavioural and psychosocial factors contributed little to the explanation of educational inequalities in mortality independent of material factors.

\section{Methodological considerations}

Several methodological remarks can be made with regard to the data used. In the first place, selection bias may have occurred as we excluded $28 \%$ of the subjects from analyses. We compared the selected subjects to the respondents of the interviews and the respondents of the postal questionnaire on mortality rate, level of education, age, gender, and the explanatory factors. The three populations were similar with regard to all factors except for the mortality rate. As expected in our selection, in which people with severe chronic disease were excluded, the mortality rate was lower than in the other two groups. As this was the case for all levels of education, we do not expect it has strongly affected our results. Furthermore, results may be different for men and women. We carried out the analyses separately for men and women,

\section{Key points}

- Low educational attainment, a marker of low socioeconomic position, has consistently been associated with an increased risk of mortality. The mechanisms underlying this association are not completely understood. Multiple pathways (material, behavioural, and psychosocial) almost certainly underlie the inequalities and these pathways probably are interrelated.

- The relative importance of different pathways in the explanation of educational inequalities in mortality is not well known.

- Material factors contribute most to the explanation of mortality inequalities.

- Part of the contribution of material factors was through psychosocial factors and to a lesser extent through behavioural factors. Part of the contribution of psychosocial factors was via behavioural factors.

- Behavioural and psychosocial factors contributed little to the explanation independent of material factors.

however the limited sample size has serious limitations to the interpretation of these results. Careful interpretation suggests that selected explanatory factors for the explanatory models would have been very similar for men and women. Furthermore, in men material factors seem to be more important for the explanation than in women, and in women in general less of the inequalities was explained by the selected explanatory factors.

Furthermore, the data were self reported, several variables were proxies, selection mechanisms may not have been sufficiently excluded, and both the study population and the follow up time were limited in size. Because of the limited size of the population and the follow up time there is considerable statistical uncertainty in the hazard ratios and thus also in the percentages calculated from the hazard ratios. Therefore the percentages change should not be interpreted as absolute numbers, but as indication of relative importance.

Finally our results depend on the selection of explanatory factors used in this study. We based the selection of explanatory factors on literature, ${ }^{9} 152728$ and made a well balanced selection of probably the most important explanatory factors from the three different groups. With regard to work related factors we decided not to include them as only $45 \%$ of the respondents were employed in 1991, and work related factors were only weakly related to mortality. Work related factors may be more important for other health outcomes, and probably they will be more important in populations with a large proportion of employed people..$^{29-31}$ Inclusion of more or other explanatory factors (for example, quality of housing, dietary intakes, area characteristics) may result in different estimates of the contributions of material, behavioural, and psychosocial factors to the explanation of educational inequalities in mortality, however we do not expect major changes in the conclusions. To establish whether the explanatory factors included in this study

\section{Policy implication}

Successful interventions to improve the material circumstances of lower educated people are probably the best strategy for reducing educational inequalities in mortality. 
adequately cover the material, behavioural, and psychosocial pathways, future research with more extensive databases should attempt to reproduce our results.

\section{Comparison with other studies}

The results of our analyses agree with results found by others. Like in other studies we have found that behavioural factors explain a substantial proportion of the inequalities, ${ }^{911} 32$ however material factors contribute most, ${ }^{29}$ psychosocial factors contribute partly through behavioural factors, ${ }^{25}$ and material factors contribute partly through behavioural factors. ${ }^{13}{ }^{29}$ A substantial part of the contribution of material factors was not through the behavioural and psychosocial pathways. A large direct effect of these material factors on mortality is biologically not very plausible. Social and physical environmental factors (possibly related to circumstances in the youth of the older people of the study population) may be pathways by which material factors are related to mortality, ${ }^{33}{ }^{34}$ and should be further explored. Another interesting finding is that the material, behavioural, and psychosocial factors explained most of the excess risk of the lowest educated groups, but a substantial part of the excess risk in the second highest educated group was not explained. The people in the higher educated group are younger and the causes of death are therefore probably different from those in the lower educated groups. Other explanatory factors may be needed to explain the excess risk in the higher educated group.

\section{Results and current theories}

There has been a vigorous debate on the relative importance of material and psychosocial factors to the explanation of inequalities in health. ${ }^{5835}$ The "(neo)materialist" explanation suggests that inequalities result from macro level forces (for example, economic and social policies), that lead to a differential exposure to material disadvantage. ${ }^{65}$ On the other hand advocates of the psychosocial explanations argue that relative material disadvantage is likely to be more important for the explanation of health inequalities than absolute disadvantage, because health inequalities are found in rich countries as well as in poorer countries and there is little relation between average income and life expectancy in richer countries. ${ }^{8}$ Our study provides empirical evidence that is of relevance to this discussion although not all material and psychosocial factors are the same: it suggests that material factors contribute importantly to the explanation of health inequalities, and that their contribution is much larger than that of a set of psychosocial factors. Although our results therefore support the "(neo)materialist" view, our results also support the psychosocial view in the sense that psychosocial factors seem to form an important pathway by which material factors exert their effect on health inequalities, and that psychosocial factors also contribute to the explanation independently from material factors. Most importantly the results indicate that both should be taken into account simultaneously in attempts to explain educational inequalities in mortality.

\section{Implications}

Reducing socioeconomic inequalities in health are an important challenge for health policy worldwide. ${ }^{36}$ In several countries, including the Netherlands, committees have given recommendations and targets for policy intended to reduce inequalities in health. ${ }^{37-39}$ Recommended interventions include topics related to socioeconomic position, material factors, behavioural factors, psychosocial factors, and healthcare services. $^{38}{ }^{39}$ Our results indicate that successful interventions to improve the suboptimal material situation of people are probably the best strategy for reducing educational inequalities in mortality. Interventions on adverse behavioural and psychosocial factors should take into account that these factors are partly a result of suboptimal material conditions.

\section{ACKNOWLEDGEMENTS}

The authors would like to thank Ilse Oonk and Roel Faber for effectuating and carefully constructing the longitudinal database. We are thankful to the participants for their willingness to participate in the GLOBE study.

\section{Authors' affiliations}

F V A van Oort, F J van Lenthe, J P Mackenbach, Department of Public Health, Erasmus MC, University Medical Centre, Rotterdam, Netherlands Funding: the Netherlands Health Research and Development Council (ZON) and the Ministry of Public Health, Welfare and Sports financially support the GLOBE study. The GLOBE study was initialised and is being carried out by the Department of Public Health of Erasmus Medical Centre in Rotterdam in collaboration with the Public Health Services of the city of Eindhoven and region of Southeast Brabant. FvL is supported by a grant from the Netherlands Organisation for Scientific Research (NWO grant number 904-66-104).

Conflicts of interest: none declared.

\section{APPENDIX}

The calculation of independent and indirect contributions was as follows. For each combination of two groups of explanatory factors three models were assessed. For example for material factors and psychosocial factors:

(1) Educational level + confounders + material factors

(2) Educational level + confounders + psychosocial factors

(3) Educational level + confounders + material factors + psychosocial factors

The independent contribution of psychosocial factors was determined by the percentage change of the hazard ratios for educational level attributable to the inclusion of psychosocial factors (model 3) to a model already containing material factors (model 1). Thus the independent contribution of psychosocial factors is calculated as the percentage reduction of the hazard ratios of model 3 minus the percentage reduction of the hazard ratios of model 1. The overlap between material and psychosocial factors was then calculated by subtraction of the independent contribution of psychosocial factors from the total contribution of psychosocial factors (model 2). This overlap was defined as the indirect contribution of material factors through psychosocial factors. The independent contribution of material factors was calculated by subtraction of the overlap from the total contribution of material factors (model 1). Identically we assessed the independent (from material factors) contribution of behavioural factors, the independent (from behavioural factors) contribution of material factors, and the contribution of material factors through behavioural factors and the independent (from psychosocial factors) contribution of behavioural factors, the independent (from behavioural factors) contribution of psychosocial factors, and the contribution of psychosocial factors through behavioural factors.

\section{REFERENCES}

1 Kunst AE, Mackenbach JP. The size of mortality differences associated with educational level in nine industrialized countries. Am J Public Health 1994;84:932-7.

2 Mackenbach JP, Kunst AE, Cavelaars $A E$, et al. Socioeconomic inequalities in morbidity and mortality in western Europe. The EU Working Group on socioeconomic inequalities in health. Lancet 1997;349:1655-9.

3 Mackenbach JP, van de Mheen H, Stronks K. A prospective cohort study investigating the explanation of socio-economic inequalities in health in the Netherlands. Soc Sci Med 1994;38:299-308. 
4 Goldman N. Social inequalities in health disentangling the underlying mechanisms. Ann N Y Acad Sci 2001;954:118-39.

5 Macleod J, Davey Smith G. Psychosocial factors and public health: a suitable case for treatment? J Epidemiol Community Health 2003;57:565-70.

6 Lynch JW, Davey Smith G, Kaplan GA, et al. Income inequality and mortality: importance to health of individual income, psychosocial environment, or material conditions. BMJ 2000;320:1200-4.

7 Wilkinson RG. Socioeconomic determinants of health. Health inequalities: relative or absolute material standards, BMJ 1997:314:591-5.

8 Marmot M, Wilkinson RG. Psychosocial and material pathways in the relation between income and health: a response to Lynch et al. BMJ 2001;322:1233-6.

9 Lantz PM, House JS, Lepkowski JM, et al. Socioeconomic factors, health behaviors, and mortality: results from a nationally representative prospective study of US adults. JAMA 1998;279:1703-8.

10 Blane D, Bartley M, Davey Smith G. Disease aetiology and materialist explanations of socioeconomic mortality differentials. Eur J Public Health 1997;7:385-91.

11 Davey Smith G, Blane D, Bartley M. Explanations for socio-economic differentials in mortality. Evidence from Britain and elsewhere. Eur J Public Health 1994:4:131-44.

12 Steptoe A, Wardle J, Pollard TM, et al. Stress, social support and healthrelated behavior: a study of smoking, alcohol consumption and physical exercise. J Psychosom Res 1996;41:171-80.

13 Schrijvers CT, Stronks K, van de Mheen HD, et al. Explaining educational differences in mortality: the role of behavioral and material factors. Am J Public Health 1999;89:535-40.

14 Stronks K, Mheen van de H, Mackenbach JP. Achtergronden van sociaaleconomische gezondheidsverschillen. Een overzicht van literatuur en een onderzoeksmodel. T Soc Gezondheidsz 1993;71:2-10.

15 Taylor SE, Seeman TE. Psychosocial resources and the SES-health relationship. Ann N Y Acad Sci 1999;896:210-25.

16 Meer van der JBW. Equal care, equal cure? Socioeconomic differences in the use of health services and the course of health problems. [Thesis]. Rotterdam: Department of Public Health, Erasmus University Rotterdam, 1998.

17 Garretsen HFL. Problem drinking. Determination of prevalence, influencing factors and possibilities for prevention. [In Dutch]. [Thesis]. Lisse: Swets and Zeitlinger BV, 1983.

18 CBS. Questionnaire life situation research. [In Dutch]. Voorburg, Heerlen: CBS, 1989.

19 Ormel J. Difficulties with living or difficult life. [In Dutch]. [Thesis]. Groningen: Rijksuniversiteit Groningen, 1980.

20 Rotter J. Generalized expectancies for internal versus external control of reinforcement. Psychol Monogr 1966;80:1-28.

21 Hendriks AAJ, Ormel J, van de Willige G. Long lasting difficulties measured with a self-assessment questionnaire and semi structured interview: a theoretical and empirical comparison. [In Dutch]. Gedrag Gezondh 1990;18:273-83.

22 van Tilburg TG. Received and desired support in the light of experiences with loneliness. [In Dutch]. [Thesis]. Amsterdam: Vrije Universiteit Amsterdam, 1988.

23 Schreurs P, Tellegen B, Vromans ISY, et al. The development of the Utrecht coping list. [In Dutch]. [Thesis]. Utrecht: Vakgroep Klinische Psychologie, Rijksuniversiteit Utrecht, 1983.

24 Cox DR. Regression models and life-tables. J R Stat Soc B 1972:34:187-220.

25 Lynch JW, Kaplan GA, Cohen RD et al. Do cardiovascular risk factors explain the relation between socioeconomic status, risk of all-cause mortality, cardiovascular mortality, and acute myocardial infarction? Am J Epidemiol 1996;144:934-42.

26 Stronks K, vandeMheen HD, Looman CWN, et al. Behavioural and structural factors in the explanation of socio- economic inequalities in health: an empirical analysis. Sociol Health III 1996;18:653-74.

27 McGinnis JM, Foege WH. Actual causes of death in the United States. JAMA 1993;270:2207-12

28 Marmot MG, Davey Smith G. Socio-economic differentials in health. The contribution of the Whitehall Studies. J Health Psychol 1997;2:283-96.

29 Sacker A, Bartley M, Firth D, et al. Dimensions of social inequality in the health of women in England: occupational, material and behavioural pathways. Soc Sci Med 2001;52:763-81.

30 Schrijivers CT, van de Mheen HD, Stronks K, et al. Socioeconomic inequalities in health in the working population: the contribution of working conditions. Int J Epidemiol 1998;27:1011-18.

31 Borg V, Kristensen TS. Social class and self-rated health: can the gradient be explained by differences in life style or work environment? Soc Sci Med 2000;51:1019-30.

32 Pekkanen J, Tuomilehto J, Uutela A, et al. Social class, health behaviour, and mortality among men and women in eastern Finland. BMJ 1995;31 1:589-93.

33 Yen IH, Kaplan GA. Neighborhood social environment and risk of death: multilevel evidence from the Alameda County Study. Am J Epidemiol 1999; 149:898-907

34 Bosma H, van de Mheen HD, Borsboom GJ, et al. Neighborhood socioeconomic status and all-cause mortality. Am J Epidemiol 2001;153:363-71.

35 Pearce N, Davey Smith G. Is social capital the key to inequalities in health? Am J Public Health 2003;93:122-9.

36 WHO. Health 21. The health for all policy framework for the WHO region. Copenhagen: World Health Organisation, 1999.

37 Acheson D, Barker D, Chambers J, et al. Independent inquiry into inequalities in health. London: The Stationery Office, 1998.

38 Swedish National Committee for Public Health. Health on equal termsnational goals for public health. Scand J Public Health 2001;57(suppl): 1-68

39 Mackenbach JP, Stronks K. A strategy for tackling health inequalities in the Netherlands. BMJ 2002;325:1029-32. 